\title{
Architecture Speciality of Sketch Teaching
}

\author{
Ying Xu \\ Gold Mantis School of Architecture and Urban Environment \\ Suzhou University \\ Suzhou, China
}

\begin{abstract}
This article in view of the art institute of architecture speciality and the general architecture speciality basic course and the difference between the different of education and the education as the object of, respectively, were analyzed, and put forward the basic course of material and skin texture is introduced into the design sketch of the course, through the analysis of case will also be able to arouse the students' creativity, as well as to the architecture design of each professional teaching has certain enlightening and guiding significance.
\end{abstract}

Keywords-material; texture; design sketch

\section{ANALYSIS ON SKETCH TEACHING OF ARCHITECTURE SPECIALITY}

Currently, the teaching contents and manifestation patterns of our design sketch are relatively single, teaching contents merely involve structure sketching and light and shade tone sketching; manifestation patterns stay on the single hand-drawn presentation with single techniques and backward teaching concepts, the existing ideology of teachers still rests on the basis of "Su school". We are not making total negation of "Su school", but rather we need to acquaint the connotation of modern design sketch teaching. To go back to training object body, we will have to follow the basic structure of modern education and endow the cultivating objects with the quality of comprehensive development.

The sketch of various design specialties in architecture differs from traditional sketch. Design sketch is a basic course to cultivate creative design, and its teaching process should emphasize on training conception and imagination as well as cultivating creativity, modeling, spatial thinking and other basic capacity of students. Design sketch enables students to master a variety of modeling factors through various stages of teaching: the mutual relationship among contour, proportion, structure, light and shade, texture, etc.; meanwhile, it enriches students' ability of spatial thinking: contradictory relations among joggling, positive-negative, concave-convex, separation-reunion, empty-full, etc. of objects. Hence we need to seize the core of "creativity" and penetrate it throughout the whole process of sketch teaching, continuously improve student observation, imagination and creativity.

\section{ANALYSIS ON INNOVATION OF COURSE ARRANGEMENT FOR SCIENCE ST UDENTS}

Many domestic design schools enroll students from science students and art students, among which science students have a relatively weak art foundation, many students start from scratch and they have difficulty in making conversion of thinking model and entering training state, thus effective guidance is required to help them quickly get new ways of learning. Before art students enter school, they have received good basic teaching of sketch, but their thinking is still basically fixed on emotional feelings of observation and logical analytical thinking capacity is weak. Therefore, teachers should make corresponding adjustments of course content for different students, the key to our success in the artistic design education lies in whether teaching should be based on emotional or rational bas is.

\section{CUltivat ION OF ST UDENT S' CREATIVE ABILITY}

\section{A. Exert Joint Efforts, Achieve Interactive Teaching}

As for sketch basic courses of design speciality, the training mode of placing static objects may well cultivate students' creativity, static objects may be placed randomly such as suspending, hanging upside down, etc., students may also select, increase and decrease objects while drawing, organize the scene composition and infuse their own thoughts and concepts, and change original passive learning to active interaction between teaching and learning. Besides, they can improve learning motivation and sense of active participation. Drawing tools and papers are subject to free choice without limitation, techniques can also be diversified.

\section{B. Penetrate Artistic Appreciation, Highlight Composition and Style of Design Sketch}

Aesthetic education should permeate into the teaching of design sketch. Nowadays, most students almost have no art foundation, and after a period of adapting process, their molding ability of objects may vary widely due to different receptivity and perception. Taking artistic appreciation as the core of sketch training is the best choice to solve the declining professional quality of students and their jagged levels. The composition of a picture will change aesthetical standard under fixed thinking and improve one's artistic thought and aesthetic judgment. "Fig. 1" 

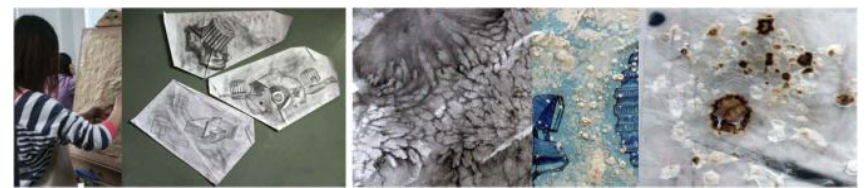

Fig. 1. Students try to draw on kraft paper and rubbed texture, cutting and folding the papers.

Training of creative thinking is a process led by teachers and acting on students' subjective initiative. A creative design sketch should combine composition and image, material integration and application of rich techniques will stimulate more inspiration of students, resulting in rich visualized symbols.

\section{CASE ST UDY AND ANALYSIS ON SKETCH EXPERIMENT COURSE TEACHING IN VARIOUS DESI GN SPECIALITIES OF ARCHITECTURE}

\section{A. Incorporate Material Integration and Texture Concept into Structure Sketching}

Since the students we enrolled basically have no basis, so they are encouraged to paint boldly in class and without using measuring tape, to observe and feel the proportion of objects with eyes.

After getting familiar with structure sketching in the first phase, the production of some materials and texture can be introduced to increase the atmosphere of the picture. In teaching links, students learn and experience the cognition, perception, practice, appreciation, etc. from shallower to deeper. By experiencing the colorful visual phenomena in life, they can understand the relationship between life elements and texture, and the intimate connection between life and art. Encouragement and presentations of teachers are required in guiding students to discover beauty in life, express beauty, enjoy beauty, and create beauty. "Fig. 2"

While expressing figurative realistic paintings, texture can reproduce the rich and varied features of object surface. The visual haptic effects of texture induce people to get close to or distance from special interfaces.
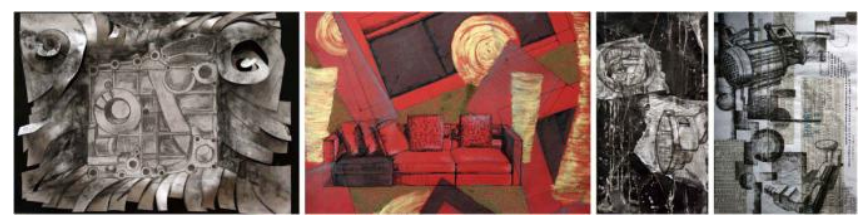

Fig. 2. Outstanding student works by introducing material and texture into structure sketching.

\section{B. Exploration on Re-Design of Plane and Elevation Composition by Applying Material and Texture}

There is a great diversity of teaching methods of creative sketch, by introducing some typical life materials and conducting presentation of various techniques, enabling students to understand the role of material and texture throughout the drawing, giving rise to practice of divergent thinking. So me methods summarized from teaching practice are given below: First, arrange students to observe, record and re-create each face of material object, such as scattering, reorganization, exaggeration, distortion of pictures; second, express a determined creative theme by combination of materials, collages and rub of various materials, creation of texture and other means; third, explore the selection and application of new tools and new materials through the creative process of design sketch. "Fig. 3" Of course, the method and process of creative sketch is a matter of opinion, it is important to train students' images modelling. By design sketch training, students will learn to observe, understand the deep sense of the purpose of learning, infuse consciousness of modern design and improve design capability.
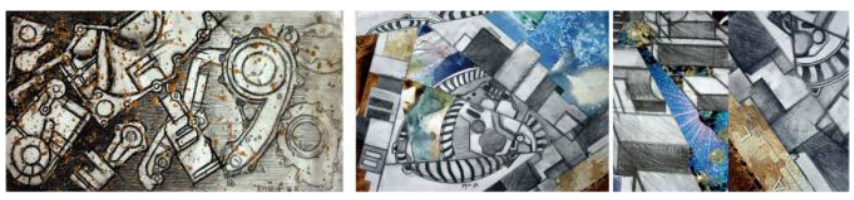

Fig. 3. Toss drops of gold and silver pigment to form irregular dots effect. Clip and collage with colored ads paper of magazine.

\section{Relationship between Emotional Experience and Material Texture}

In teaching, each student's emotional level is different, which is multi-leveled, they also have certain natural instincts, some students are filled with pure emotion, aiming to express realistic objective things vividly. Also some students have rich life and artistic experience, their subjective emotions are gradually abundant in painting, they transform objects and re-arrange the picture by relying on their true feelings, thus breaking ordinary composition and creating a new self-reality. Such emotional experience is usually based on the student's life experience, educational level, artistic accomplishment and other different factors, which is the main reason why people have different feelings and different emotional manifestations towards the same group of static objects. "Fig. 4"

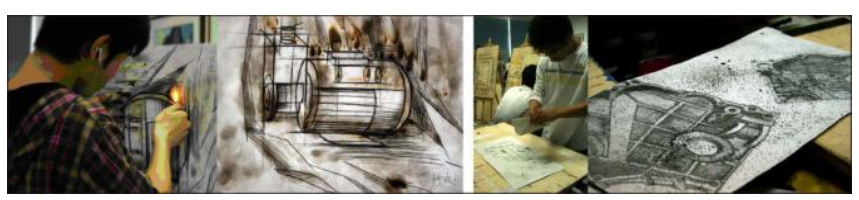

Fig. 4. Produce texture using fire, black paint, charcoal ash and other materials

\section{Analysis on Material Texture in Art Works Endowing Painting Composition an Appropriate Extent}

By integrating texture training in sketching process of students can develop their ability of observation and perception, so that they can design using texture effects in life, create texture effects and beautify works. We focus on stimulating student's learning emotion during teaching, enabling them to use and master different texture effects to create paintings. However, how to guide students to make good use of texture features and perform works purposefully and how to achieve harmony and perfection become teaching difficulties. "Fig. 5" 


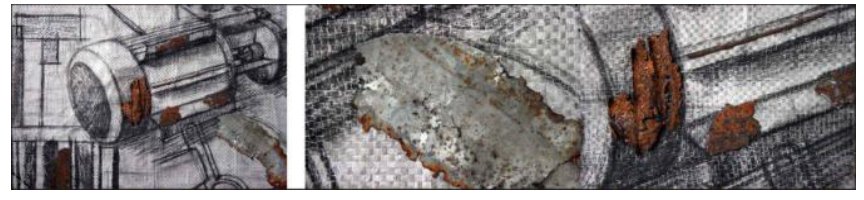

Fig. 5. Painting on jute bags, texture of jute bag and iron sheet forms contrast.

\section{E. Spatial form Association Practice}

Since architecture design speciality students will face indoor and outdoor space modeling problems in the future, so structure analysis and transformation capability is particularly important in teaching process, the training from plane to three-dimensional spatial expansion capacity will lay a solid foundation for students' in-depth study later. Therefore the training is implemented as key teaching points in sketch experimental course teaching. "Fig. 6"
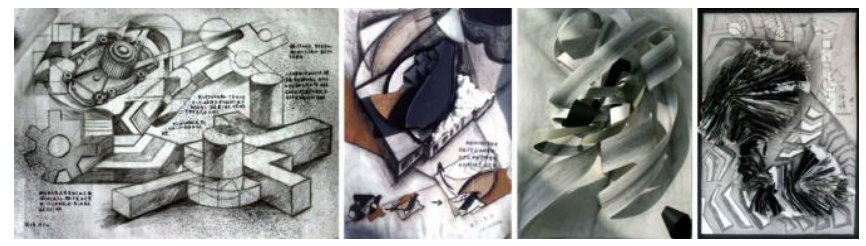

Fig. 6.

\section{KEY POINT ANALYSIS OF STUDENT S' HOMEWORK}

The introduction and application of many methods of fabricating texture during study and practice including rubbing, moxibustion, collages and other integrated techniques, have activated classroom atmosphere, students also found a lot of fun in practice and created some preferable works. "Fig. 7", "Fig. 8", "Fig. 9", "Fig. 10"
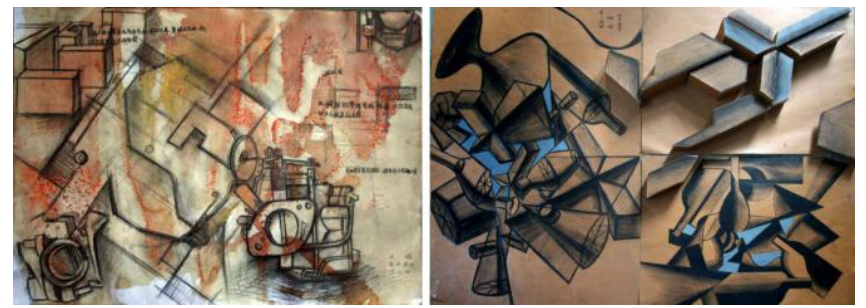

Fig. 7.

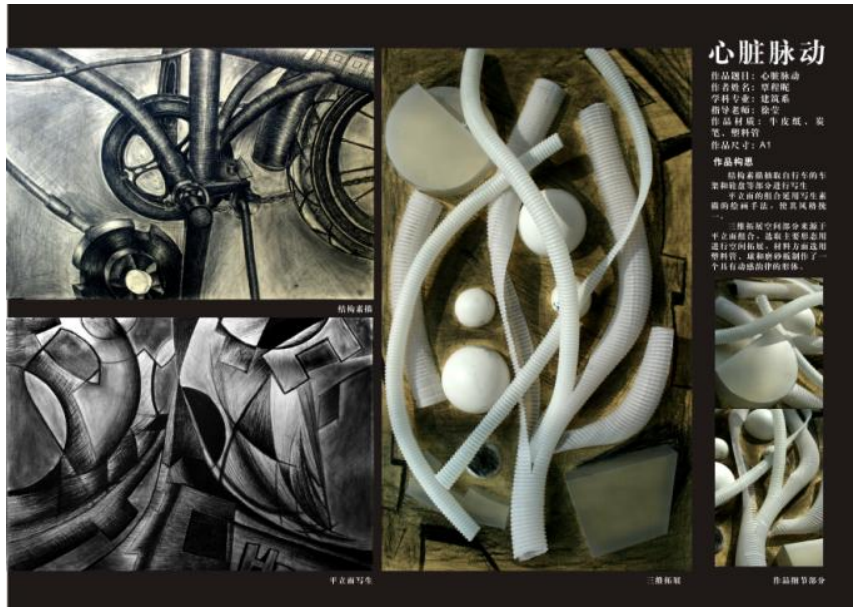

Fig. 8.

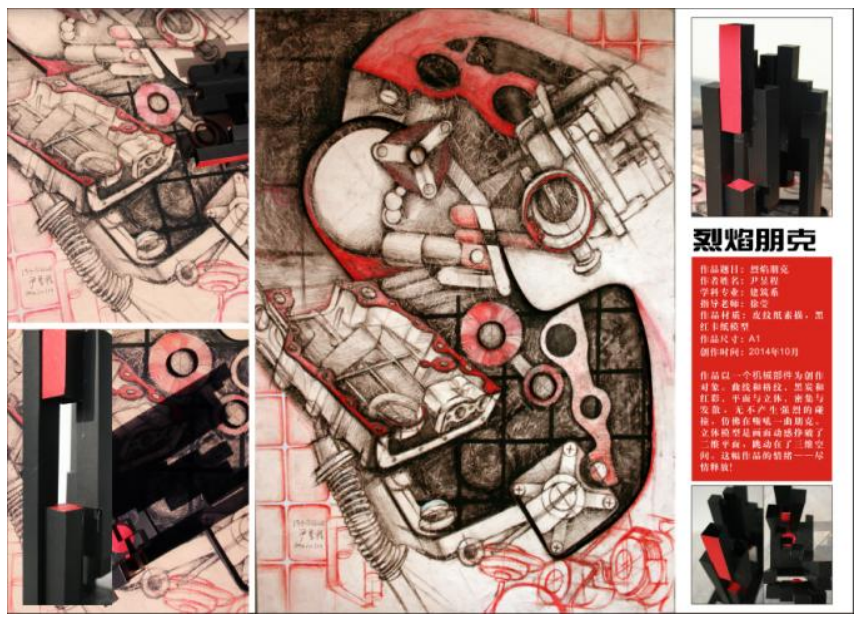

Fig. 9.

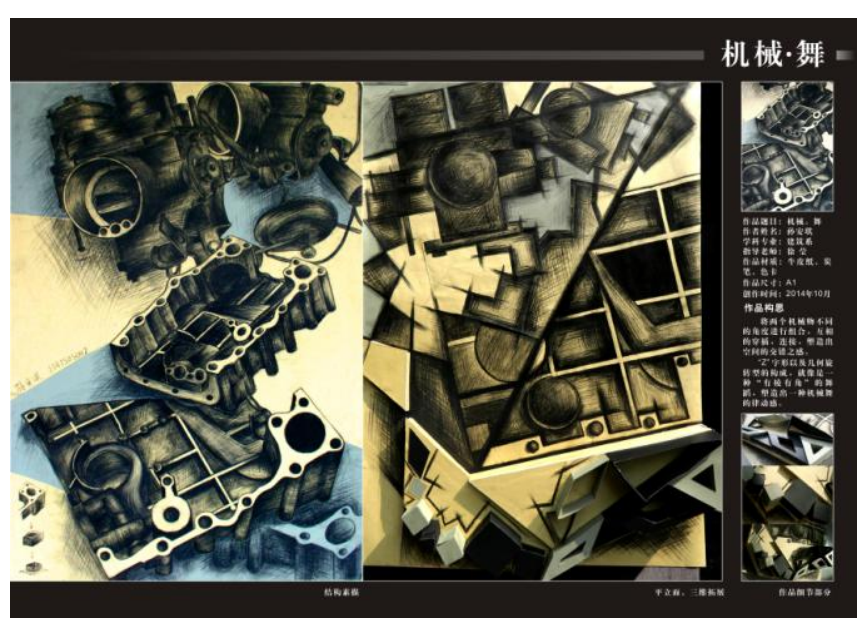

Fig. 10.

\section{RESULTS REPORT, ANALYSIS AND RECOMMENDATIONS}

After the end of the course, each student will have their own feelings and experiences. 
Students enrolled by architecture speciality of our school are all science students without art foundation, and they were fully aware of their advantages in speciality during teaching process, established discipline confidence and manifested amazing ability in detailed analysis of material objects. Due to careful and rigorous thought as well as analytical ability of science students, they'll have more detailed analysis in reconstruction of plane and elevation and three-dimensional spatial expansion. However, structural analysis and spatial imagination ability are particularly important throughout design sketch. The accumulation of adequate homework and sketches after class and provision of regular guidance and analysis are necessary.

\section{SUMMARY AND OUTLOOK}

Expand teaching ideas, introduce the concept of material and texture into the structural sketch teaching of interior design based on the student's own characteristics, combining course characteristics and local conditions, forming courses suitable for the speciality, and effectively improving sketch teaching quality of the speciality.

\section{ACKNOWLEDGMENT}

Thank the works provided by Wang Rui, Ji Yudan, Lu Fang, Chen Boyan, Zhuyan, Cao Liangliang, Gong Liuyan, Guo Meicun, Fu Chen, Yang Yinjie, Mao Yongqiang from Grade 2008 Interior Classes, as well as Qin Chengni, Yin Yucheng, Sun Anqi, Chen Yijing, Cai Rui, Jing Yue from Grade 2013 Architecture.

\section{REFERENCES}

[1] Zhou Zhiyu Set Sail in Art [M] Shanxi Shanxi People's Publishing House 2009.10 P66

[2] Zhou Zhiyu Design Basis Teaching [M] Beijing Peking University Press 2007.10 P33

[3] Gu Daqing Design and Sense of Sight [M] Mainland China Building Industry Press 2002.10 P108

[4] Wang Huabin Composition of Picture Texture [M] Beijing People's Fine Arts Publishing House 1995.6 P3-P5 